Journal of the Scholarship of Teaching and Learning, Vol. 20, No. 2, October 2020, pp. 86-98.

doi: 10.14434/josotl.v20i2.26577

\title{
Portraits of Undergraduate Discipline-Specific Thinking: Guiding Students from Novice to Proficient Learner
}

\author{
Patricia Stovey \\ University of Wisconsin-La Crosse \\ pstovey@uwlax.edu \\ Tiffany Trimmer \\ University of Wisconsin-La Crosse \\ ttrimmer@uwlax.edu
}

\begin{abstract}
This case study presents our experiences, insights, and the pedagogical techniques used to guide undergraduate students toward discipline-specific thinking. It demonstrates the role of studentcentered practices in moving students from what we categorize as novice to proficient, a common goal in rite-of-passage courses across the disciplines. Our study follows two semesters of students in undergraduate college-level Historiography and Historical Methods courses to identify common stumbling blocks encountered when learning contextualiziation (our discipline-specific thinking skill). We analyze students' habits of mind, cognitive behaviors, and assumptions when learning to think differently. We present a qualitative portrait demonstrating the range of student cognitive behaviors as they attempt to move towards proficiency. As experts immersed in our fields of study and its practices, we can sometimes forget that what comes second-nature to us is far from natural to our studentsregardless of their enthusiasm. We may overestimate the background knowledge that our students have, and underestimate the brain bandwidth required when trying - for the first time — to think differently. Keywords: discipline specific thinking, cognitive overload, metacognition, pedagogy
\end{abstract}

\section{Part 1: Introduction}

When working with undergraduates it is common to encounter obstacles that are predictable yet also confounding. In history, contextualized thinking is one of these. Students who become history majors or minors oftentimes have memorized an impressive array of historical "facts" and are able to describe the importance of contextualization, but when asked to actually use that information to explain the events or assumptions that helped to drive past actions, they fall short of expectations (Grim et al., 2004). This situation is not specific to history. No matter the major, most undergraduate students' concept of being — thinking like-a teacher, mathematician, scientist, or historian generally diverges from reality.

Regular readers in the scholarship of teaching and learning are quite familiar with key markers that differentiate novice vs expert thinking: chunking information, recognizing patterns, intuitive and flexible thinking, problem solving, and the ability to pick and choose information out of a vast array of stored knowledge (Willingham, 2009; Bransford et al., 2000). One reason experts are able to do these things is because of the years they have spent immersed in their field. Simply put, experts - in contrast with novices whose learning has often emphasized breadth over depthare experts in part because of the time they have devoted to their work (Bransford et al., 2000). But another reason that experts think the way they do is because they have already cleared their way past stumbling blocks particular to their discipline: understanding the role of computation in mathematical thinking for example, or coming to terms with conditionalized knowledge in political science or sociology. Because it is our role to teach students to begin to think like experts in their 
chosen field, it is important that we focus on helping them to move through what Pace calls "bottlenecks" so that they can continue their transition away from novice thinking (Pace, 2007).

This study emerged from a required methodology and historiography course at a small Midwestern college campus situated near the Mississippi River. It analyzed the difficulties two semesters of undergraduate history majors and minors encountered as they learned to think contextually. While the class may be geared for majors and minors, contextualized thinking is a skill that is applicable across an array of disciplines, specifically because it requires a degree of empathy and flexible thinking. Our study used in-class readings, class discussion, and reflective journal writing to assess the quality of novice students' declarative knowledge about the thought processes associated with historical contextualization. Then, we investigated how students made the transition from declarative knowledge to procedural knowledge by having them decide what context information would be needed to interpret a primary source collection. Primary sources are particularly difficult for novice historical thinkers because although these documents are steeped in time and place, their context is rarely spelled out. The manuscript collections the students used for this semester-long assignment came from local archives on campus and the city's public library. Despite being a campus of only about 10,000 students — in a city of less than 100,000_our students had a wealth of choices, and therefore, the luxury of choosing collections that were both personally interesting and within walking distance. Collectively these circumstances created an ideal environment from which to observe students' thinking as they attempted to transition from declarative to procedural knowledge.

\section{Part 2: Framing the Pedagogy and Research Context}

The problems we encounter when teaching students to think like a classroom teacher, biologist, or historian are difficult in part because they oftentimes challenge students' understanding of the world around them. How humans organize information and make sense of things can frequently create inaccuracies, such as when students depend on observation alone to explain scientific phenomena. These theories, Leah Savion calls a natural part of how people think. They are a part of a "biological need for ordering and controlling" our world, and while they are "revised with use and with intellectual maturity ... they are not normally tested (voluntarily) against scientific theories or social facts, nor are they subjected to metacognitive tests, such as the attempt to detect inconsistencies" (Savion, 2009). As a result, student thinking oftentimes conflicts with that of the teacher whose expertise has become second nature.

It is important to note that while undergraduate-level historiography coursework is designed to change student thinking, it does not expect to transform novice thinkers into experts - in this case historians. Expertise in any given field is a combination of past learning and past experience and the result, of an "average of ten years, or ten-thousand hours of deliberate practice in a domain" (Bogard et al., 2000). Our work sought to move students' thinking into alignment with what Dreyfus and Dreyfus (2005) call "proficient learners," those able to identify and evaluate problems, prioritize, adapt, and apply. In our study, students' ability to move from declarative to procedural knowledge demonstrated their transition to proficient learners. Although not truly experts, proficient learners practice disciplinary thinking that is more in line with their chosen field and the experts they hope to become.

To effectively change students' thinking and create proficient learners requires teaching strategies that use student-centered learning in which the focus is on "process over product," metacognition, and the misconceptions that oftentimes shape understanding. In teacher-centered classrooms, students' false assumptions or novice thinking is rarely dislodged. They may adopt vocabulary or parrot back a discipline's touchstones, but still retain the false beliefs that maintain

Journal of the Scholarship of Teaching and Learning, Vol. 20, No. 2, October 2020. josotl.indiana.edu 
their logical world order. In contrast, "super active learning," where students are put in the role of teacher, most effectively dislodges inaccurate thinking because in the process of instructing others, students must recognize their level of cognition, understand their learning style in contrast with others, and communicate information in a real-world application (Savion, 2009).

A pre-existing course assignment, The National History Day in Wisconsin Friendly Finding Aid $(\mathrm{FFA})^{1}$ put our students in the role of teacher and served as the primary way we judged their movement from a declarative understanding of the thinking skills associated with contextualization to a procedural one. In this project students chose, interpreted, and then contextualized a selection within a manuscript collection with the goal of effectively communicating their narrative to eighth grade National History Day (NHD) students_their target audience. Their goal was to prepare their work for publication on the FFA website, which, after additional revision, generally occurred the following semester. To accomplish our objectives, we engaged our students in three kinds of writing activities that captured their thinking: reflective journal entries, a contextualization to-do list, and a contextualization essay.

First, early in the semester, reflective writing questions prompted students to explain their working understanding of the purpose of historical contextualization and the kinds of mental activities it involves. Class readings laid bare the ways historians think about evidence, and the way context is sometimes used when there are gaps in the historical record. Each reading assignment was then followed by a reflective writing entry with prompts used to capture the students' thinking. For example, after one reading in which an historian showed how he created a narrative that was in line with known context but not a part of the featured primary source, the students were asked: "what role does historical context information play in history-writing?" Questions like this aimed to capture the students' declarative knowledge. But they also served as a launching point for robust class discussion and generated a repository of writing reflections that each student could refer back to as they worked on their to-do lists and contextualization essays.

Next, after having chosen the collections they wanted to review for their FFA, students were tasked with contextualizing their manuscript collection's evidence. First they predicted the background information essential in a contextualization to-do list, then used that list to guide their research for the contextualization essay. These requirements, the to-do-list and final contextualization essay, were the measures used to understand how well the students transitioned from declarative to procedural knowledge-in essence, began thinking like historians. Setting the students up to succeed in this component of the FFA project required us to scaffold their work and build in regular references to their already-established declarative knowledge. For instance, class discussions often referred back to prior analysis of contextualization as a representative example of what the students were being asked to create. The to-do list gave us insight into how students' prior knowledge and (potential) misconceptions about history and the work of historians either aided, or limited, their ability to develop disciplinary-specific thinking skills. It also became an important way

\footnotetext{
${ }^{1}$ The National History Day in Wisconsin Friendly Finding Aid (FFA) is a website collection of archival finding aids that allows middle and high school students to easily find and use locally available primary source documents. The site is designed for students doing research for National History Day (NHD), a nationwide program and academic contest focused on historical research and the broad-based skills developed through historical research. It uses the same organization and format of a traditional finding aid, but is more accessible to younger scholars because it provides them a single narrative (or limited number of narratives) within a larger collection. The FFA gives students new to primary source research the joy of successfully using archival sources to create storylines that place their region within larger historical processes. The National History Day in Wisconsin Friendly Finding Aid was funded in part by a grant from the Wisconsin Humanities Council (WHC), with funds from the National Endowment for the Humanities. For more information on the WHC go to: www.wisconsinhumanties.org. To visit the FFA website, see: www.friendlyfindingaid.com For more information on National History Day go to: www.nhd.org.
}

Journal of the Scholarship of Teaching and Learning, Vol. 20, No. 2, October 2020. josotl.indiana.edu 
we captured students' thinking, with the goal of seeing them use their recorded insights as they determined the context required to understand their own collection. In particular, we looked at students' ability to apply content knowledge or problem solve when content knowledge was lacking. (As will be explained in greater detail below, students' lack of content knowledge proved to be an important bottleneck halting some students' ability to transition beyond declarative knowledge.)

Finally, as the assignment's title implies, the contextualization essay required students to write an essay demonstrating the decisions they made about contextual relevance. It tested students' transition from novice to proficient learners, specifically their ability to choose information from a vast array of knowledge, adapt, prioritize, and apply. As the culmination of the semester-and this study-it allowed us to see where students got stuck, which skills they used to get unstuck, and how in the process of becoming proficient learners they demonstrated disciple-specific thinking.

Our study used our department's Historiography and Historical Methods course because it is the point in our curriculum where majors and minors are formally introduced to the analytical skills historical contextualization requires. This course is our discipline's "rite of passage," designed to introduce and practice history-specific thinking, and open students' eyes to the real world of the field they have chosen. ${ }^{2}$ Ideally it is taken during students' sophomore year. But because students change majors, individual sections of Historiography and Historical Methods are regularly made up of sophomores, juniors, and seniors. This results in a mixed classroom population with a wide range of exposure to, and practice with, historical thinking skills as well as a wide range of prior content knowledge. Some students have no experience with primary sources, and no knowledge about why historians contextualize primary sources, or the intellectual effort it involves. Others may display declarative knowledge, being able to explain the general purpose of historical context information, but not be able translate that into to any kind of procedural knowledge, defined as "knowing how and when to apply various procedures, methods, theories, styles, or approaches" (Ambrose et al., 2010). In contrast advanced juniors and seniors have already completed upper-level courses that required them to practice contextualization in class assignments and discussions. They generally have the necessary procedural knowledge to complete a contextualization task, but not the declarative knowledge needed to explain the historical thinking skill they are using.

This same variation in student preparedness also applies to content knowledge. For example, one student in our study had not yet taken any of the 200-level general survey courses or completed the 100-level world history survey. However, in that same section there were other students who had nearly completed all their survey and upper-level elective requirements. (See Table 1 for an overview of the characteristics of our study's participants.) Varying degrees of content knowledge cut across our study, directly impacting some students' ability to shift from declarative to procedural knowledge. For some, their lack of content knowledge limited further growth. Oftentimes these students' failures can be seen as a reflection on poor teaching or insufficient effort of the part of students, but pedagogical research points to other possibilities. In Why Students Don't Like School, Willingham (2009), argues that a student's compartmentalized thinking is not so much an issue of a novice's inability to recognize the importance of expert thinking, as it is symbolic of cognitive overload. For students new to both manuscript collections and contextualizing evidence, this would mean that the challenge of taking in the array of information that makes up any primary source collection has flooded them with so much new information that there is no cognitive space

2 The historiography and methodology course in this study caps enrollment at twenty students, however semesters with double sections (40 students) are not unusual. Single and double sections have done the same work as described in this study.

Journal of the Scholarship of Teaching and Learning, Vol. 20, No. 2, October 2020. josotl.indiana.edu 
left for reasoned contextualization. Here, cognitive overload may explain why many students' early attempts to think like experts falls flat.

The primary source collection they chose to work with also influenced the success of students' contextualization work. Some chose collections that aligned with previous university-level coursework; in essence they set themselves up for "near" transfer of learning. But other students chose collections based on factors such as personal or political interest, document style, or perceived readability, which were outside of their content background. This second category of students ended up with the greater challenge of a "far" transfer of learning. For these students, not only were the learning contexts dissimilar, (high school history or social studies classrooms versus university-level classrooms), but potentially the content learning as well (science or women's studies versus history). While all teachers encourage their students to think across the curriculum, students often do not readily or "successfully apply relevant skills or knowledge in novel contexts" (Ambrose et al., 2010).

Lastly, it is important to note that while much of the growth in students' discipline-specific thinking came from class readings, discussion, and assignments, many of the students featured in this article also set up appointments with reference librarians (highly encouraged) or took advantage of one-on-one problem-solving office hour consultations (common in history teaching) for help finding relevant secondary sources or other faculty members to consult. In a few cases, struggling students were directly handed sources containing the information needed to contextualize their collections. As Pace (2011) has pointed out, in contrast with many other disciplines, history is a field that lacks a firm consensus in ways others might consider fundamental — such as what constitutes truth and fact. Yet, as in all disciplines, what a student does with information-even if placed directly in front of them-is out of the teacher's control.

Table 1. Characteristics of Novice Contextualizers in Study

\begin{tabular}{|c|c|c|c|c|c|c|c|}
\hline $\begin{array}{l}\text { Student } \\
\text { ID }\end{array}$ & $\begin{array}{l}\text { History } \\
\text { Major or } \\
\text { Minor }\end{array}$ & $\begin{array}{l}\text { Total } \\
\text { Number } \\
\text { of } \\
\text { Credits }\end{array}$ & Year & $\begin{array}{l}\text { Test } \\
\text { Credits* }\end{array}$ & $\begin{array}{l}\text { Credits from } \\
\text { Survey } \\
\text { Courses } * *\end{array}$ & $\begin{array}{l}\text { History Credits } \\
\text { (Survey and } \\
\text { Content } \\
\text { Courses) } \\
\end{array}$ & $\begin{array}{l}\text { Transfer } \\
\text { Student } \\
\mathrm{Y} / \mathrm{N}\end{array}$ \\
\hline F1 & Major & 77 & Junior & 6 & 9 & 12 & $\mathrm{~N}$ \\
\hline F2 & Major & 33 & Sophomore & 0 & 3 & 3 & $\mathrm{Y}$ \\
\hline F4 & Major & 29 & Freshman & 0 & 0 & 0 & $\mathrm{~N}$ \\
\hline F5 & Major & 24 & Freshman & 3 & 3 & 6 & $\mathrm{Y}$ \\
\hline F6 & Minor & 126 & Senior & 0 & 9 & 9 & $\mathrm{~N}$ \\
\hline F7 & Major & 33 & Sophomore & 0 & 6 & 6 & $\mathrm{Y}$ \\
\hline F8 & Major & 28 & Freshman & 3 & 6 & 9 & $\mathrm{~N}$ \\
\hline F9 & Minor & 96 & Senior & 3 & 6 & 12 & $\mathrm{~N}$ \\
\hline F10 & Minor & 25 & Freshman & 3 & 3 & 3 & $\mathrm{Y}$ \\
\hline F11 & Minor & 90 & Senior & 0 & 15 & 27 & $\mathrm{Y}$ \\
\hline F12 & Major & 61 & Junior & 0 & 12 & 12 & $\mathrm{Y}$ \\
\hline F13 & Major & 57 & Sophomore & 0 & 9 & 12 & $\mathrm{~N}$ \\
\hline F14 & Major & 35 & Sophomore & 6 & 12 & 12 & $\mathrm{~N}$ \\
\hline F15 & Major & 33 & Sophomore & 3 & 9 & 12 & $\mathrm{Y}$ \\
\hline F16 & Minor & 93 & Senior & 3 & 9 & 15 & $\mathrm{~N}$ \\
\hline F17 & Minor & 57 & Sophomore & 0 & 3 & 3 & $\mathrm{Y}$ \\
\hline F18 & Major & 53 & Sophomore & 0 & 12 & 15 & $\mathrm{~N}$ \\
\hline S1 & Major & 58 & Sophomore & 0 & 9 & 12 & $\mathrm{Y}$ \\
\hline S2 & Major & 111 & Senior & 6 & 12 & 24 & $\mathrm{Y}$ \\
\hline
\end{tabular}

Journal of the Scholarship of Teaching and Learning, Vol. 20, No. 2, October 2020. josotl.indiana.edu 


\begin{tabular}{|l|l|l|l|l|l|l|l|}
\hline S3 & Major & 80 & Junior & 0 & 9 & 15 & $\mathrm{~N}$ \\
\hline S4 & Major & 46 & Sophomore & 0 & 3 & 3 & $\mathrm{~N}$ \\
\hline S5 & Major & 68 & Junior & 0 & 3 & 3 & $\mathrm{Y}$ \\
\hline S6 & Major & 13 & Freshman & 6 & 9 & 9 & $\mathrm{~N}$ \\
\hline S7 & Major & 34 & Sophomore & 0 & 3 & 3 & $\mathrm{~N}$ \\
\hline S8 & Major & 107 & Senior & 6 & 12 & 21 & $\mathrm{Y}$ \\
\hline S9 & Major & 122 & Senior & 0 & 6 & 15 & $\mathrm{~N}$ \\
\hline S10 & Major & 77 & Junior & 3 & 9 & 24 & $\mathrm{~N}$ \\
\hline S11 & Major & 15 & Post-Bac & 0 & 0 & 9 & $\mathrm{~N}$ \\
\hline S12 & Major & 73 & Junior & 3 & 12 & 12 & $\mathrm{~N}$ \\
\hline S13 & Major & 51 & Sophomore & 0 & 12 & 12 & $\mathrm{Y}$ \\
\hline S14 & Minor & 93 & Senior & 3 & 9 & 18 & $\mathrm{~N}$ \\
\hline S15 & Major & 74 & Junior & 0 & 6 & 6 & $\mathrm{~N}$ \\
\hline S16 & Minor & 80 & Junior & 0 & 6 & 6 & $\mathrm{Y}$ \\
\hline S17 & Minor & 103 & Senior & 6 & 12 & 21 & $\mathrm{~N}$ \\
\hline
\end{tabular}

* Credits earned in AP high school coursework.

** Taken at the university

\section{Part 3: Portrait of Novice-Level through Proficient-Level Thinking}

What follows is a case study of two semesters of students making the transition from declarative to procedural knowledge. It demonstrates common teaching challenges, effective pedagogical techniques, and students' habits of mind essential to be aware of when guiding undergraduates towards discipline-specific thinking skills. We have organized this section into two parts. First, we summarize the status of students' declarative knowledge and how that shaped their ability to execute tasks that required procedural knowledge. Then, we present students' transition towards proficiency, ranging from those who were largely unsuccessful, to students able to think flexibly enough to problem-solve when they encountered unexpected challenges. We provide examples of where our students got stuck when trying to build declarative knowledge or apply procedural knowledge in a new context, and how they progressed towards successful application of discipline-specific thinking skills. It is our hope that the pedagogical content knowledge gained through out study will help teachers more effectively structure classroom activities, assignments, and interventions that support students as they move toward proficiency (Bransford et al., 2000).

\section{Accurate and Inaccurate Declarative Knowledge: Writing Reflections}

Most of the students we observed were able to describe the thinking skills associated with the task at hand in relatively accurate terms. Their reflective journal entries demonstrated accurate declarative knowledge, for example defining historical contextualization as a process that helps explain why a primary source author makes the arguments that they do, or why primary sources contain the information they do. "History without context would be a set of facts and dates listed.

Contextualization helps us to understand" the viewpoint of people who lived through past events, one student explained. Another wrote that historical contextualization "helps explain why certain events happened and how the events came to be. If you don't know what is happening in a region during the time period then you don't know how people are motivated and why they do what they do." The way students such as these wrote about the purpose of historical contextualization suggested a level 
of learning that we believed would allow them to successfully make the transition to the "super active learning" tasks of the to-do list and contextualization essay.

But as Savion (2009) has demonstrated, the cognitive trend of "belief perseverance" can result in students clinging to incorrect assumptions about the nature of discipline-specific knowledge or thinking skills, even as they use language that appears to be reasonably accurate. In our study, misperceptions about how historians actually work occasionally created stumbling blocks that hindered students' abilities to change their thinking. For example, several students fell back on earlier beliefs about history as a truth-telling or fact-checking activity, despite course readings and discussion that challenged this prior assumption. This mindset proved especially problematic when students who thought their role was to be truth-seekers assumed that their contextualization task was finished as soon as they found a "fact" that corresponded to their prior content knowledge. In reality, an expert would do something very different_- consider a wide range of factors and select the ones that were most relevant to explaining the phenomenon they were observing in the evidence. Our observations illustrate a crucial point about working with students making the difficult transition away from novice thinking: inaccurate declarative knowledge about how one should think about, or work with, information in a discipline-specific way requires focused pedagogical intervention. In our study, guiding students in a direction that more accurately reflected the task at hand required structured class discussions where they could hear other students and the instructor describe analytical tasks correctly, feedback on writing exercises that illustrated examples of the thinking skills they ignored, and the chance to see their thinking change through multiple drafts of an assignment.

Even students with generally competent declarative knowledge sometimes demonstrated limited awareness of what that thinking skill involved in disciplinary practice. For example, one student wrote a generally accurate-but incredibly broad-definition of contextualization in their reflective journal entry and seemed uncertain how to narrow the list of possibilities based on the relevance of information. They explained the scope of context information as "all the background knowledge of what is going [on] in that time and place. It can range," they continued, "from a number of things such as what type of people lived there and what their culture was all about. It also gives you information about where they came from, so the history before them." While an expert has learned to think in categories or patterns of information and select only what is relevant from a range of possibilities, this novice thinker had not. The student also had a misperception about how historians actually work, believing that their job was to collect all available information on a subject, rather than prioritize by focusing on only what would help explain the evidence under examination and excluding extraneous details.

This student's extremely broad definition foreshadowed problems ahead, especially the in the next task that required implementation of procedural knowledge in the contextualization essay. Students like the one above, acted as fact-collectors seeking to amass information on all the general topics they envisioned, without regard for relevance. While an expert has an instinctive working knowledge of the scope of information a project can realistically involve and how to discard categories of information that are irrelevant, students making their way from novice to proficient learners have not yet developed this kind of judgement. In this early phase of experience, some novice-level students cannot appreciate their tendency to over-generalize; it does not occur to them that the scope of analysis they are proposing is much too broad. As a result, students conceptualizing their task in an overly broad manner tended to struggle with articulating the relevance of information and being able to link (or lump together) similar categories of information.

Our study found that putting students in a position which required them to think about the implications of casting their net so broadly often led them to realize their inaccurate assumptions about the scope of historical context information they would need to research. For example, group

Journal of the Scholarship of Teaching and Learning, Vol. 20, No. 2, October 2020. josotl.indiana.edu 
discussion of their to-do lists allowed students to imagine the scope of information they were proposing and compare that to other students. Brainstorming activities (group or individual) that asked students to generate concrete examples for broad categories of information they put on their to-do lists also led them to evaluate the appropriateness of their ideas and make adjustments. Discussion questions or reflective writing prompts that asked them to explain why some kind of information did — or did not—fit with the topic under investigation also helped them appreciate the concepts of relevance and identify potential linkages between categories of information.

\section{The Spectrum of Procedural Knowledge from Novice to Proficient: Contextualization To- Do Lists and Contextualization Essays}

Students who lacked both declarative knowledge of discipline-specific thinking skills and content knowledge marked the weaker end of the spectrum. Their written work tended to center on easilynoticed, surface-level details instead of researched, external information about the historical context that would have been more helpful to the task at hand. For example, one student's to-do list and contextualization essay focused entirely on biographical details already provided in the collection they chose to work with, rather than information about historical trends such as Progressive Era political philosophies that might have shaped their primary source author's legal career or living conditions in the largely rural area where he served. Even though guided class discussions and reflective journal entry questions emphasized that historical context information would be found in secondary sources, the student continued to draw information from the author's own writings (primary sources), attempting to use it as historical context instead.

Cognitive overload seems to partially explain the student getting stuck here: overwhelmed by the steps necessary to apply procedural knowledge to a new task, they were unable to go beyond surface-level information. This first-semester sophomore's limited prior knowledge of major themes in U.S. History also seem to have been a contributing factor. It's vital to acknowledge that novice students do not know what they do not know. Because limited content knowledge leaves them unaware of potential alternative explanations for the phenomenon they are analyzing (in this case the evidence in the primary sources they were tasked with contextualizing), they may assume they have produced a sufficient answer and not understand why an instructor views their work as incomplete.

In our study, moving this kind of novice student towards a proficient understanding of the discipline-specific thinking skill required a multi-pronged strategy over the course of the semester. Because our Historiography and Historical Methods course sections tended to have a mix of advanced and less advanced students in the same class (see Table 1), in class discussions we used the responses of students who were closer to proficient as representations of the kind of thinking novices should be aiming for. Working through extended examples of explanations put together by closer-to-proficient students also provided illustrations these less experienced students could refer back to when they got stuck in their own work.

Having the instructor discuss examples of how they would approach the assigned task likewise provided an opportunity to model discipline-specific thinking skills in a step-by-step fashion. Because disciplines such as history often have students read the work of historians as course assignments, another way we encouraged novices to envision the components of the task at hand was having them identify a passage from a course reading they believed worked as a good example of the thinking skill they were being asked to demonstrate. Whether leveraging the example of other students' work, the instructors' own professional practice, or examples in course readings, providing a steady stream of consistent examples of what successful solutions to the task looked like was imperative for guiding the novice students in our study. These kinds of pedagogical interventions

Journal of the Scholarship of Teaching and Learning, Vol. 20, No. 2, October 2020. josotl.indiana.edu 
allowed us to provide a steady stream of models for discipline-specific thinking skills which students could refer back to when they got stuck.

Limited content knowledge also made it difficult for some students to sufficiently contextualize the primary sources in the collections they were working with. For example, one student's project involved records collected over the lifespan of a local German-American athletic club. The club's declining membership over the first half of the twentieth century was evident from the materials the student was working with, but the student struggled to identify plausible explanations for that decline. The student had a prior sense that German-Americans faced discrimination during World War I. (It's unclear whether this belief came from earlier coursework, family lore, consumption of popular culture, or another source.) Their prior history course work was limited to two survey courses, neither or which would have covered German-American communities in the early twentieth century. As a result, they attributed the loss of membership entirely to antiGerman sentiment during World War I, overlooking other possible factors like assimilation of thirdor fourth-generation descendants of immigrants, or the emergence of athletic clubs that offered membership to multiple ethnic groups.

Students like this who stopped working on their context explanations after the first idea they came up with were sometimes doing so because they failed to realize that there might be more than one factor at work. In situations such as this we found that putting books (or articles, or web addresses, or colleagues' email addresses) into novice students' hands was only successful if they already possessed an awareness that historical thinking involves multi-causal explanations. Again, they did not know what they did not know. In such cases, it's also possible that well-intentioned instructor feedback encouraging the student to keep looking for additional information to improve their context explanation may have provoked a cognitive overload response from the student. Unable to conceive of potential alternative kinds of information that may be relevant, the student became overwhelmed and stopped working on the task.

In disciplines where complex causality, or multiple contributing factors working simultaneously to produce a phenomenon is the norm, novice students may need extra practice understanding when to stop an explanation or when to dig deeper. In our study, class discussions that asked students to volunteer an array of potential causal factors_-and justify each one's significance-were used to model the multi-layered thinking required for proficiency. Because the contextualization essays involved multiple drafts, instructor comments were also used to signal places in students' thinking that were underdeveloped or misguided. ${ }^{3}$

Limited content knowledge also led students to produce work with contextual parameters that were much too general, or that failed to take into account the specific nature of the evidence in the primary source collection being researched. For example, in a to-do list, one student listed the following kinds of context information they intended to research as: "social attitudes...major players involved, nature of evidence, networks/relationships, role of individual, geography-place, people's identity in relation to place, economic context, gender roles (homefront duties)." Here the student's declarative knowledge about what contextualization and the discipline of history involves seemed to be colliding with shallow content knowledge. They have a sense of the language used by historians and the categories of information that historians might consider when contextualizing a primary source, and are able to organize their ideas into categories (or chunks) of information the way an expert would. But, the unevenness of their prior knowledge becomes apparent in the varying degrees of specificity or generality they use to label those categories of information.

\footnotetext{
${ }^{3}$ We did not use student peer-to-peer review of contextualization essay drafts in our study. But this is another potential way to help novice students identify places where their thinking and causal explanations were underdeveloped.

Journal of the Scholarship of Teaching and Learning, Vol. 20, No. 2, October 2020. josotl.indiana.edu
} 
In our study, we observed that such students also tended to struggle with discerning relevance. Rather than ranking potential context factors according to their ability to explain the phenomenon they were analyzing (the evidence in their primary sources), they tended to put all potential causal factors on equal footing. Helping such students move further towards proficiency and a sense of sufficient detail required tasks that asked them to provide specific evidence for each category they identified as relevant. In this manner, they were often able to identify the places in their context explanations where their thinking was, or was not, too general. Here our goal was to help them build an internalized sense of what was sufficiently detailed enough to work for the task at hand and be able to recognize which parts of their explanation require further revision.

It is also possible that a student who is moving towards proficiency may have developed expectations about what a disciplinary practitioner does, but because they lack sufficient experience (and therefore judgement) they fail to recognize the conditional nature of relevance. In our study, we observed several instances where students replicated already existing models from secondary sources written by professional historians, regardless of whether or not they fit their own context explanation. In one instance, a student who worked with a mid-nineteenth century travel diary kept by a trans-Atlantic migrant initially assumed their contextualization essay must include equal sections on economic, political, and social issues, despite those categories not equally shaping what the diarist chose to write about. Similarly, a student whose primary source collection featured news clippings and other ephemera about local and national baseball teams emphasized the sport's role in early twentieth century Americanization processes and its cultural symbolism throughout their contextualization essay. However, their collection's materials contained limited evidence related to either of these themes.

In both cases, these students correctly recognized that they needed to seek out a multi-causal explanation for the context of the collection's evidence. But while experts can quickly disregard concepts or information that do not fit the task at hand, these students were unable to prioritize the various context factors and jettison those that didn't relate. Instead, they turned to familiar categories from secondary sources they had read and like the student described in the previous section, placed all their context information on an equal footing. In these instances, students were modeling what they believed a scholar in their discipline should do, without realizing that disciplines such as history do not have "one size fits all" solutions. Instead the goal of the discipline-specific thinking they were being asked to demonstrate involved determining what kinds of evidence require further explanation, then seeking information that will explain them.

It appears that these novices could not yet appreciate that the specifics of their own primary source collection required them to develop an alternative strategy to make sense of the evidence at hand. In this instance, assumptions about what a disciplinary practitioner should do made their thinking inflexible. In our study, moving such students beyond this impasse required classroom activities that modeled problem-solving and adaptability while dispelling their belief that the correct answer could only involve what someone else had previously proposed or published. During class discussions of work-in-progress, alternate explanations and essay section outlines proposed by instructors and students who were closer to proficiency helped signal to novice students that they needed to adjust their thinking and revise their explanations to make them relevant to the actual evidence they were working with. Having discussion participants articulate the logic behind their choices (thus making their thinking transparent) was another key to helping novice students realize alternative solutions for the contextualization essay task. Repetition of these kinds of exercises in the classroom, and reinforcing flexible thinking via instructor comments to students, were also crucial to helping novice students develop a less rigid mindset towards historical contextualization tasks over the course of the semester.

Journal of the Scholarship of Teaching and Learning, Vol. 20, No. 2, October 2020. josotl.indiana.edu 
In our study we discovered that the tendency of some students to stop after the first answer oftentimes stalled their transition towards more flexible habits of mind. For the two students described above, only the student working with the migrant's diary was able to revise their assumptions about which context factors mattered most by the final version of their contextualization essay. However, the student working with the baseball-related collection remained stuck on the context factors identified in their first draft. In this case, despite several attempted pedagogical interventions, the student was uncomfortable moving beyond what they had come to believe were the accepted answers that other disciplinary practitioners had already provided for their topic.

The above examples highlight a range of challenges novice students exhibited while trying to think in a discipline-specific way. But in our study we also observed examples of students whose application of discipline-specific thinking skills approached proficiency. By the final drafts of their contextualization essays, students were moving beyond their first ideas towards complex causal explanations, adapting and problem-solving when confronted with limited information, and conceptualizing their subject matter in a holistic fashion. These behaviors demonstrated what we considered hallmarks of proficient learners' thinking, specifically their ability to choose information from a vast array of knowledge, apply only the information relevant to the evidence at hand, and think flexibly enough to adapt when initial ideas provided insufficient explanations.

Many of our students were ultimately able to identify the broader causal factors shaping the evidence in their primary source collections. The following statement, which one student used to begin the third draft of their contextualization essay on a Jewish anti-defamation organization, serves as a representative example: "To understand the B'nai B'rith collection, you must first understand the history of anti-Semitism." Complex causal explanations were also provided by another student who profiled letters written by a regiment of Union soldiers who adopted an anti-slavery stance during the American Civil War. In their contextualization essay, the student provided multiple reasons why the regiment's soldiers supported emancipation, distinguishing between soldiers motivated by Christian beliefs that slavery was immoral, those that saw slavery as a political issue threatening national unity, those that hoped freeing slaves would undermine the labor pool keeping the Confederacy viable, and those influenced by the anti-slavery sentiments of the colonel who led their regiment. In such cases, students demonstrated proficiency by understanding that a larger, complicated set of beliefs (anti-Semitism) or multiple possible causes (religious or political beliefs, labor constraints, the example set by a commanding officer) were shaping the evidence they were working with, and then working to sufficiently explain that intersecting set of causes.

Another way some of the students in our study demonstrated proficiency was by problemsolving when they encountered a lack of available information about the evidence in their primary source collections. Confronted by a lack of published secondary sources relevant to the local immigrant community oral histories they were researching, one student integrated information taken from other secondary sources which described a similar (albeit larger) immigrant community in another part of the state. Their contextualization essay made appropriate use of the information from the second (non-local) community, after explaining the limited local secondary sources that made it necessary to look elsewhere. When confronted with an obstacle that challenged their ability to contextualize an important causal factor, rather than giving up, they changed the parameters of their search for secondary sources (including other cities beyond the immediate location of their collection). They thought about what they knew about the multi-directional migrations of the immigrant community involved, then began looking for secondary sources linked to those other places the migrant group had moved.

We also observed instances of another category of proficient-level thinking, evaluating a task holistically. In the contextualization essay for the B'nai B'rith collection described previously, the

Journal of the Scholarship of Teaching and Learning, Vol. 20, No. 2, October 2020. josotl.indiana.edu 
student's explanation moved back and forth between multiple scales of context factors, switching between Eastern Europe and Germany, the United States, and the Israeli-Palestinian conflict as it described different areas of activism detailed in the local chapter's meeting minutes and surviving pamphlets. The previously-described student profiling the local immigrant oral histories also broadly conceptualized the scope of necessary context information. In their contextualization essay, they explained that "it can be easier to understand why [these] communities in the US gravitated around church and religion, if one understands how religious society was setup under the Ottoman Empire." In these cases, students' contextualization essays responded to particular aspects of their chosen primary source collections by shifting between micro, meso, or macro level explanations as appropriate. In doing so they contrasted markedly with the novice-level students described at the beginning of this section who tended to build their entire contextualization essays around either surface-level details or the initial ideas from their to-do lists.

\section{Part 4: Conclusion}

Thinking in a discipline-specific way is a fundamental skill that all professors want their undergraduate students to accomplish. In history, contextualized thinking is one important way historians make sense of the past, but it is also as Sam Wineburg has famously stated, an "unnatural act," and therefore not easy to teach or learn (Wineburg, 2001). As experts immersed in our fields of study and its practices, we can sometimes forget that what comes second-nature to us is far from natural to our students - regardless of their enthusiasm. We may overestimate the background knowledge that our students have, and underestimate the brain bandwidth required when tryingfor the first time - to think differently. In addition, we may not fully appreciate the beliefs students bring into our classrooms. Like all undergraduates, history students have assumptions about what it means to be a professional. To these students their ideas feel natural, are largely unquestioned, but are also many times false. Ultimately, it is these pet beliefs - regardless of the discipline - that create bottlenecks to undergraduates' ability to think like the professionals they want be.

This article presented our experiences, insights, and the pedagogical techniques used to guide undergraduate students toward discipline-specific thinking. Writing reflections allowed students an opportunity for self-reflection, provided content for small group discussion, and allowed students to confront limitations in their current understanding of key concepts. These student-centered activities provided the opportunity for modeling, feedback on ideas, and because all reflections were collected in a single document, the chance for students to look back and see their intellectual growth over time. Students employed brainstorming followed by guided discussion and debate over the lists they had made. Small group and class-wide discussions of their work-in-progress allowed students to engage with their peers in the process of problem solving. And when necessary, students received targeted intervention. All of these activities facilitated a classroom culture of problem-solving, with students encouraged to leverage their own thinking to assist classmates trying to accomplish the same task.

Our study demonstrated the effectiveness of student-centered strategies in teaching upperlevel thinking skills. Students' contextualization essays showed their ability to shift from declarative to procedural knowledge. They problem solved when confronted with unexpected challenges and addressed the gaps in their knowledge. However our study also showed the power of beliefperseverance when trying to develop discipline-specific thinking. For some, remnants of earlier assumptions about history's relationship with truth and facts remained even at the end of the semester, and despite the above student-centered practices employed.

How can this be? Like all disciplines, history has particular challenges that get in the way of a student's transition to proficient-level thinking. In history, differing levels of content knowledge can

Journal of the Scholarship of Teaching and Learning, Vol. 20, No. 2, October 2020. josotl.indiana.edu 
create a hurdle that some students - at this point in their professional development - cannot clear. They may cognitively freeze, or revert to what they think they know as the "correct answer" (in this case a kind of return to the naïve understanding of history's relationship with facts). For our discipline, students' ability to problem solve and begin to think historically is related to their level of content knowledge. Other disciplines have equivalent stumbling blocks. As teachers, we tend to take it as an article of faith that students will progressively improve their thinking skills as they move through the curriculum. Some clearly do, but for those who stumble, understanding the patterns of behavior the novices in our study exhibited will help everyone who teaches rite-of-passage courses meet their students' needs.

\section{References}

Ambrose, S., Bridges, M.W., DiPietro, M., Lovett, M.C., \& Morman, M.K. (2010). How learning works: Seven research-based principles for smart teaching. San Francisco: Jossey-Bass.

American Historical Association. (2016). AHA history tuning project: 2016 history discipline core. Retrieved from https://www.historians.org/teaching-and-learning/tuning-the-historydiscipline/2016-history-discipline-core.

Bransford, A., Brown, A. L., Cocking, R. R., Donovan, M. S., \& Pellegrino, J. W. (2000). How people learn: Brain, mind, experience, and school. Washington D.C.: National Academy Press.

Bogard, T., Sableski, M., Arnold, J., \& Bowman C. (2017). Minding the gap: Mentor and pre-service teachers' ability perceptions of content-area literacy instruction. Journal of the Scholarship of Teaching and Learning, 17(4), 44-66.

Brundage, A. (1997). Teaching research and writing to upper division history majors: Contexts, sources, rhetorical strategies. The History Teacher, 30, 451-59.

Drefyus, H. L., \& Dreyfus S. E. (2005). Expertise in real world contexts. Organizational Studies, 26(5), 779-792.

Grim, V., Pace, D., \& Shopkow, L. (2004). Learning to use evidence in the study of history. New Directions in Teaching and Learning, 98, 57-65.

Leinhardt, G. (1994). History: A time to be mindful. In Leinhardt, G., Beck, I.L., Stanton, C. (Eds.). Teaching and learning history (pp. 209-55). Hillsdale, NJ: Lawrence Erlbaum Associates.

Lyon, L. J. (2015). Development of teaching expertise viewed through the Dreyfus model of skill acquisition. Journal of the Scholarship of Teaching and Learning, 15(1), 88-105.

Middendorf, J., Pace, D., Shopkow, L., \& Diaz, A. (2007). Making thinking explicit: Decoding history teaching. The National Teaching \& Learning Forum, 16(2), 1-4.

Pace, D. (2011). Assessment in History: The case for "decoding" the discipline. Journal of the Scholarship of Teaching and Learning, 11(3), 107-119.

Pace, D. (2017). The decoding the disciplines paradigm: Seven steps to increased student learning. Bloomington: Indiana University Press.

Popkin, J. D. (2015). From Herodotus to H-Net: The story of historiography. New York: Oxford University Press.

Savion, L. (2009). Clinging to discredited beliefs: the larger cognitive story. Journal of the Scholarship of Teaching and Learning, 9(1), 81-92.

VanSledright, B. A. (2011). The challenge of rethinking history education: On practices, theories, and policy. New York: Routledge.

Willingham, D.T. (2009). Why don't students like school?: A cognitive scientist answers questions about how the mind works and what it means for the classroom. San Francisco: Jossey-Bass.

Wineburg, S. (2001). Historical thinking and other unnatural acts: Charting the future of teaching the past. Philadelphia: Temple University Press.

Journal of the Scholarship of Teaching and Learning, Vol. 20, No. 2, October 2020.

josotl.indiana.edu 